Boise State University

ScholarWorks

4-22-2009

\title{
Capacitive Conductivity Logging and Electrical Stratigraphy in a High-resistivity Aquifer, Boise Hydrogeophysical Research Site
}

C. Jonathan Mwenifumbo

Geological Survey of Canada

Warren Barrash

Boise State University

Michael D. Knoll

Boise State University 


\title{
Capacitive conductivity logging and electrical stratigraphy in a high-resistivity aquifer, Boise Hydrogeophysical Research Site
}

\author{
C. Jonathan Mwenifumbo ${ }^{1}$, Warren Barrash ${ }^{2}$, and Michael D. Knoll ${ }^{2}$
}

\begin{abstract}
We tested a prototype capacitive-conductivity borehole tool in a shallow, unconfined aquifer with coarse, unconsolidated sediments and very-low-conductivity water at the Boise Hydrogeophysical Research Site (BHRS). Examining such a high-resistivity system provides a good test for the capacitive-conductivity tool because the conventional induction-conductivity tool (known to have limited effectiveness in high-resistivity systems) did not generate expressive well logs at the BHRS. The capacitive-conductivity tool demonstrated highly repeatable, low-noise behavior but poor correlation with the induction tool in the lower-conductivity portions of the stratigraphy where the induction tool was relatively unresponsive. Singular spectrum analysis of capacitive-conductivity logs reveals similar vertical-length scales of structures to porosity logs at the BHRS. Also, major stratigraphic units identified with porosity logs are evident in the capacitive-conductivity logs. However, a previously unrecognized subdivision in the upper portion of one of the major stratigraphic units can be identified consistently as a relatively low-conductivity body (i.e., an electrostratigraphic unit) between the overlying stratigraphic unit and the relatively high-conductivity lower portion - despite similar porosity and lithology in adjacent units. The high repeatability and resolution and the wide dynamic range of the capacitive-conductivity tool are demonstrated here to extend to high-resistivity, unconsolidated sedimentary aquifer environments.
\end{abstract}

\section{INTRODUCTION}

The measurement of formation electrical conductivity (or resistivity) in boreholes using capacitive electrodes, instead of galvanic electrodes or inductive coils, is a fairly recent development (Timo- feev et al., 1994; Mwenifumbo and Bristow, 1999). The capacitive resistivity method was used for surface measurements before borehole applications (Grard and Tabbagh, 1991). The large range in electrical properties and variety in borehole environments has led to many different designs in electrode-array geometries for galvanic and inductive measurement tools. Electrical properties of earth materials commonly are measured galvanically or inductively; they range from $100,000 \mathrm{mS} / \mathrm{m}(<0.01 \mathrm{ohm}-\mathrm{m})$ in highly conductive massive sulfides to $0.001 \mathrm{mS} / \mathrm{m}(>1,000,000 \mathrm{ohm}-\mathrm{m})$ in unaltered crystalline rocks. In addition, borehole environments can vary significantly from application to application; for example in soft sediments, boreholes generally are cased to prevent them from collapsing, but in the arctic most shallow boreholes are dry and can be cased or uncased.

Unlike the galvanic conductivity method, which requires electrodes to contact conductive media, the capacitive method requires no contact electrodes and works in plastic-cased or air-filled boreholes. Although the inductive method is a noncontact electrode system, it only works well in media with relatively high conductivity (McNeill, 1986), whereas the capacitive method works well in highly resistive conditions (>1000 ohm-m). The borehole capacitiveconductivity method initially was developed to measure highly resistive permafrost sediments (Timofeev et al., 1994) where galvanic and inductive electrical methods were unsuccessful. Similarly, the surface applications of the capacitive resistivity method are geared to environments where galvanic resistivity measurements are unsuccessful (Kuras et al., 2006).

To further the development of this method, the Geological Survey of Canada conducted a series of logging experiments in several different geologic environments: very-high-conductivity volcanogenic massive sulfide environments at the Calumet lead-zinc deposit, Quebec, Canada, and nickel sulfide deposits at Sudbury, Ontario, Canada (Elliott et al., 1999); in midrange conductivity environments of consolidated sediments in the Ottawa Valley, Ontario, Canada (Mwenifumbo and Bristow, 1999) and unconsolidated Pleistocene sediments in the Fraser Delta, British Columbia, Canada (Mwenifumbo

Manuscript received by the Editor 16 June 2008; revised manuscript received 16 October 2008; published online 22 April 2009.

${ }^{1}$ Geological Survey of Canada, Borehole Geophysics Section, Vancouver, British Columbia, Canada. E-mail: jarako@nrcan.gc.ca.

${ }^{2}$ Boise State University, Center for Geophysical Investigation of the Shallow Subsurface, Department of Geosciences, Boise, Idaho, U.S.A. E-mail: wbarrash@cgiss.boisestate.edu; mknoll@cgiss.boisestate.edu. (c) 2009 Society of Exploration Geophysicists. All rights reserved. 
et al., 1994); and in low-conductivity permafrost sediments in the Mackenzie Delta, Northwest Territories, Canada.

In this paper, we present field-logging results obtained from a series of 14 PVC-cased wells in the very-low-conductivity environment at the Boise Hydrogeophysical Research Site (BHRS), Idaho (Figure 1) (Barrash et al., 1999). Our objective in this study was twofold: (1) to assess the ability of the capacitive-conductivity method to map and refine stratigraphy at a well-characterized site located in a highly resistive, shallow, unconfined, coarse fluvial aquifer and (2) to compare the data with previously acquired induction-conductivity and neutron porosity logs to investigate the $3 \mathrm{D}$ distribution of electrical conductivity values at the BHRS.

In the following sections, we first establish the high quality of logging measurements used in this study for capacitive conductivity and porosity. Then we use statistical and signal-processing methods to examine the high degree of correlation between capacitive conductivity and porosity (with one important exception) and the poor correlation between capacitive and inductive conductivity, especially in low-conductivity portions of the system. From the capacitiveconductivity logs at the BHRS, we identify and trace the lateral continuity of a previously unrecognized electrostratigraphic unit with relatively low conductivity that is an exception to the capacitiveconductivity-porosity relationship noted above.

\section{HYDROGEOLOGIC SETTING}

The hydrogeologic setting for this study is a shallow, unconfined aquifer in unconsolidated, coarse (cobble, gravel, and sand) fluvial deposits at the BHRS (Barrash et al., 1999), a research well field developed at a cobble bar adjacent to the Boise River, $15 \mathrm{~km}$ from downtown Boise, Idaho, U.S.A. (Figure 1). Deposits at this site are the youngest in a series of Quaternary to Recent coarse fluvial deposits of the Boise River that overlie a sequence of successively older

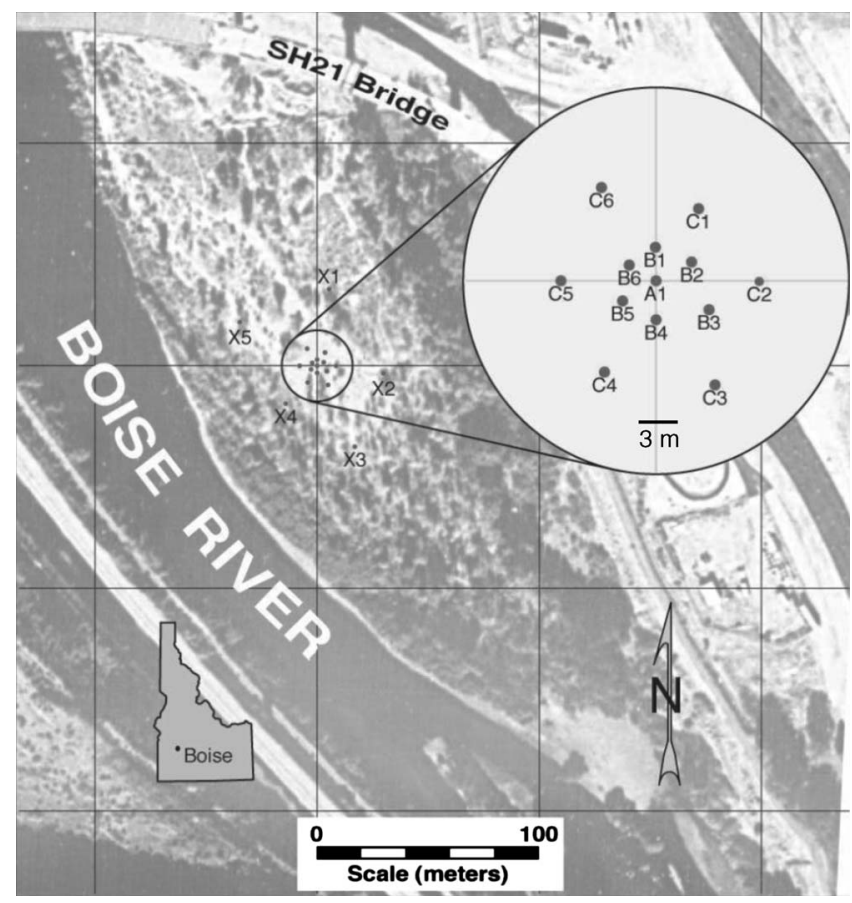

Figure 1. Location and design of the Boise Hydrogeophysical Research Site (BHRS). and higher terraces (Othberg, 1994). Outcrop and quarry exposures (Figure 2) in these terraces show features similar to those of wellstudied deposits (e.g., Jussel et al., 1994; Heinz et al., 2003), including massive cobble-and-sand sheets and sheets with weak subhorizontal layering; crossbedded and trough-crossbedded cobble-dominated facies; and sand channels, lenses, and drapes.

At the BHRS, 18 wells were cored through 18-21 m of unconsolidated cobble and sand fluvial deposits and were completed into the underlying clay. All wells were completed with $10-\mathrm{cm}$ internal diameter (ID) slotted and screened PVC casing through the fluvial aquifer. The wells were constructed with the drive-and-drill method to minimize the disturbed volume of formation outside the wells (Morin et al., 1988). With this method, the formation was allowed to collapse against the slotted casing when the drive casing was withdrawn; no gravel pack was installed (Barrash et al., 2006). Of the 18 wells at the BHRS, 13 are concentrated in the 20-m-diameter central area of the BHRS (see Figure 1) and five are boundary wells.

\section{Stratigraphy at the BHRS}

In the central area of the BHRS, the unconfined aquifer is composed of a sequence of stratigraphic units, including four cobbledominated units (units 1-4) overlain by a channel sand (unit 5) that thickens toward the Boise River and pinches out in the center of the well field (Figure 3). These coarse sediments of the aquifer are underlain by a red clay layer throughout the site and by the thin $(\sim 1 \mathrm{~m}$ thick) edge of a basalt flow that occurs between the clay and the coarse sediments in portions of the site. Of the cobble-dominated units, units 1 and 3 have relatively low porosity (mean porosities of 0.18 and 0.17 , respectively); units 2 and 4 (Figure 3 ) have higher
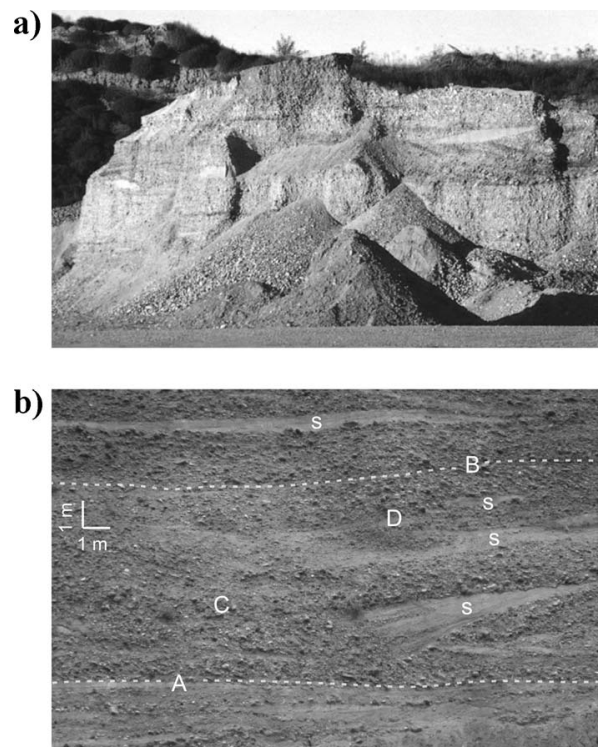

Figure 2. Quarry and road-cut exposures in the vicinity of the BHRS, showing coarse fluvial sediments analogous to subsurface deposits at the BHRS. View (b) labels the layers. A: Layers (several meters thick) showing massive or subhorizontal bedding structure or local cross-bedded structure and facies variations, especially with sand lenses. B: Laterally persistent bounding surfaces (A and B) in addition to gradual (C) and abrupt (D) changes of sedimentary structure and texture between the bounding surfaces. Note the predominance of cobble-sized framework clasts overall but also the local presence of sand bodies (S) (from Barrash and Clemo, 2002). 
mean porosities ( 0.24 and 0.23 , respectively) and more variable porosity, lithology, and facies composition (Barrash and Clemo, 2002; Barrash and Reboulet, 2004).

\section{Porosity}

We used porosity logs as reference information for sedimentary or lithologic stratigraphy and as a measure of fluid-filled volume fraction in the aquifer at the BHRS (Barrash and Clemo, 2002; Barrash and Reboulet, 2004). The logs were constructed from neutron-log measurements taken at 0.06- $\mathrm{m}$ intervals below the water table in all wells. The estimated region of influence of the logging tool is a somewhat spherical volume with a radius of perhaps $0.2 \mathrm{~m}$ (Keys, 1990). The neutron logs are quite repeatable: four runs in well C5 at
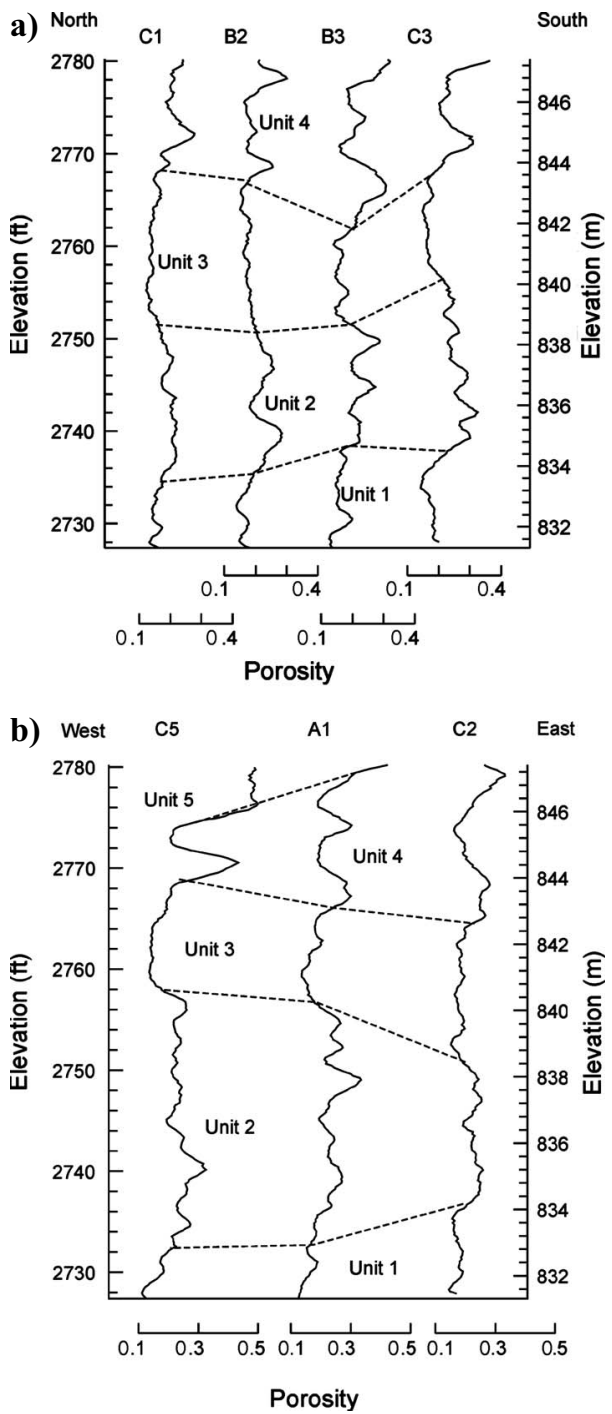

Figure 3. Cross sections showing stratigraphy interpreted from neutron porosity logs that extend from the water table to the base of the fluvial aquifer. (a) Orientation of section is in the general direction of river flow (see inset location, Figure 1). Relative horizontal well positions not to scale. Units 1-4 are cobble-dominated units. (b) Orientation of section is perpendicular to the general direction of river flow. Unit 5 is a sand channel that thickens toward the river and pinches out near the center of the well field (after Barrash and Clemo, 2002). the BHRS have correlation coefficients of 0.935-0.966 (Barrash and Clemo, 2002). Conversion of neutron counts to porosity in waterfilled boreholes is well established (Hearst and Nelson, 1985; Rider, 1996), with a petrophysical transform using high and low end-member counts associated with low and high porosity values, respectively, for a given calibrated reservoir rock such as sandstone.

Similar count equivalents for porosity are unavailable from a well at an in situ calibration site in similar coarse, unconsolidated fluvial sediments, but end-member estimates can be made from literature values for deposits such as high-porosity clean fluvial sands $(\sim 0.50)$ (e.g., Pettyjohn et al., 1973; Atkins and McBride, 1992) and low-porosity conglomerate with cobble framework and sandy matrix $(\sim 0.12)$ (e.g., Jussel et al., 1994; Heinz et al., 2003). So, working from reasonably well-constrained end-member porosity values, we estimate the uncertainty at the high end of the scale (in sand) to be $\pm 5 \%$ and at the low end to be $\pm 10 \%$. Considering the nature of the transform and recognizing the high degree of repeatability of the logs, we can expect that rank consistency of relative porosity values is maintained to the measurement noise level $( \pm 5 \%$ accuracy of counts per second).

\section{CAPACITIVE-CONDUCTIVITY LOGGING}

\section{Principle}

The simplest implementation of a capacitance is a pair of closely spaced parallel plates. A sinusoidal potential applied to the plates of a capacitor generates a corresponding sinusoidal electric field in the material between the plates. If this material is conductive, there will be a drop in the potential across the plates by an amount that is a function of the bulk conductivity. The capacitive borehole conductivity probe exploits this effect by making the strata intersected by the borehole act as the material between the plates of the capacitor in the probe, as illustrated in Figure 4.

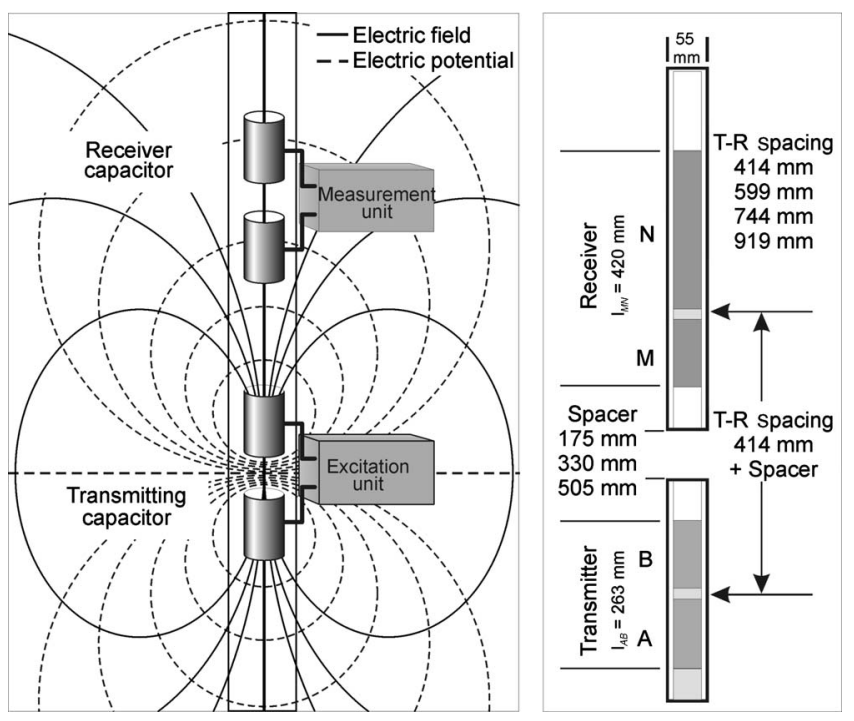

Figure 4. Principle of operation of the capacitive-conductivity probe. The probe consists of two pairs of coaxial metal cylinders forming a transmitter capacitor and a receiver capacitor, respectively. The electrode-array geometry is analogous to a galvanic dipoledipole array with variable capacitor pair spacings of $41,60,74$, and $92 \mathrm{~cm}$. The system operates at a frequency of approximately 1.0 MHz. The probe diameter is $55 \mathrm{~mm}$. 
The plates are constructed in the form of two coaxial metal cylinders separated by a sufficient distance to allow the electric field generated between them to permeate as large a volume of the formation as is practical (Bristow and Mwenifumbo, 1998). This electric field is sensed by a second capacitor constructed in the same way as, and coaxial with, the transmitter capacitor (Figure 4). Changes in the potential between the coaxial plates of the transmitter capacitor from the conductivity of the material reduce the electric field generated throughout the volume of earth material investigated. This, in turn, reduces the potential between the receiver capacitor plates, i.e., sensed as the signal and processed by the logging tool.

Further inspection of Figure 4 shows that the separation between the two capacitors has a major influence on the volume of investigation. The smaller the spacing, the smaller the volume of investigation but the better the spatial resolution of thin layers. This geometric consideration in the design of the capacitive-conductivity probe similarly applies to the two-coil inductive conductivity probe and the galvanic conductivity probe.

\section{Calibration of capacitive-conductivity against galvanic-conductivity responses}

We calibrated capacitive-conductivity data against galvanic-conductivity data; both were acquired at the Geological Survey of Canada's Bells Corners Borehole Geophysical Test Site (Mwenifumbo and Bristow, 1999). The Bells Corners drill holes are vertical, 75 $\mathrm{mm}$ (2.95 inches) in diameter, and uncased. They intersect approximately $65 \mathrm{~m}$ of Paleozoic sediments consisting of sandy dolomite, dolomitic sandstones, sandstone, and shale (Bernius, 1996; Mwenifumbo et al., 2005). These sediments are underlain by Precambrian basement rock composed of gneisses and granites. Figure 5 shows the 40-cm normal array, galvanic-conductivity data, and capacitiveconductivity data from the Bells Corners site. There is excellent agreement between the two data sets. We then used the calibrations from the Bells Corners data to recalibrate the capacitive-conductivity data from the BHRS.

\section{Data acquisition and repeatability}

The capacitive-conductivity tool used in this investigation is a prototype; at times, probe electronics fail and/or there is significant drift in the logging data resulting from temperature changes within the borehole. Therefore, the standard procedure adopted by the Geo-

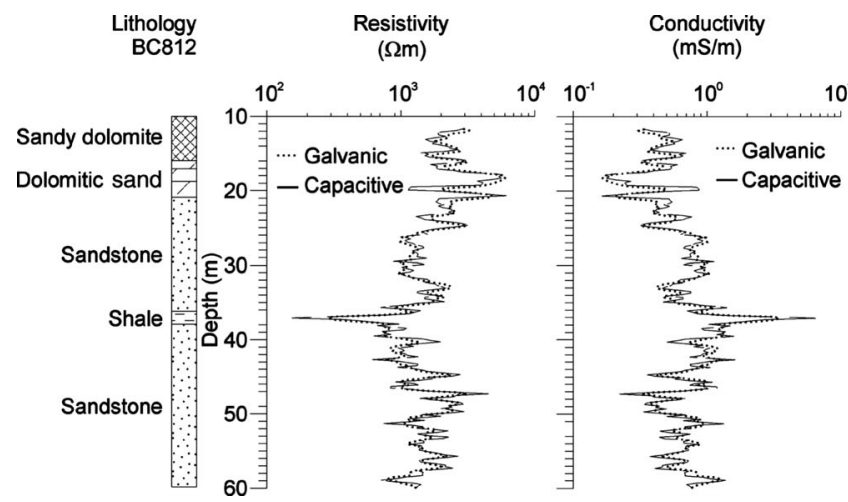

Figure 5. Galvanic resistivity log acquired with a 40-cm normal array is compared to the capacitive resistivity log at Bells Corners Borehole Geophysical Test Site. The data are compared as resistivity and conductivity (the reciprocal of resistivity -1 /resistivity). logical Survey of Canada is to acquire data during downhole and uphole runs at each borehole. Although both data sets are not used in the final data analysis, the two logs are used to check data repeatability and hence provide confidence in the quality of data when subtle anomalous features are observed.

We initially acquired several capacitive-conductivity logs in well A1 at the BHRS to examine the quality of the logging response by checking data repeatability and assessing errors in the data acquisition system. Figure 6 shows six capacitive-conductivity runs superimposed on each other and the difference between the mean of these six and each of the logging runs over the entire borehole. The overall mean difference for each run is $<0.002 \mathrm{mS} / \mathrm{m}$, generally $\leq 0.001 \mathrm{mS} / \mathrm{m}$, which is quite reasonable in terms of data repeatability. Also, average values of approximately $1-2 \mathrm{mS} / \mathrm{m}$ are similar to those determined by Oldenborger et al. (2007) and by Johnson and Miller (personal communication, 2008) from background ERT measurements in the central area of the BHRS. For reference, specific conductance of water samples from wells at the BHRS has ranged from about 165-210 $\mu \mathrm{S} / \mathrm{cm}$ (Hausrath et al., 2002).

\section{SINGULAR SPECTRUM ANALYSIS}

The wells at the BHRS intersect sediments composed of cobbles, gravels, pebbles, and sands varying with lithologic texture, sedimentary structure, and depositional process or event on the scale of a decimeter to meters in thickness (Reboulet and Barrash, 2003; Barrash and Reboulet, 2004). The information at this range of scales is captured in the capacitive-conductivity logs. One of the objectives of data processing is to look at the components of these sedimentary units at different scales through singular spectrum analysis as an independent check on the stratigraphic interpretations from porosity logs and core analyses based on professional judgment and on statistical and geostatistical analyses.

The identification, isolation, and reconstruction of signal components in a data series can reveal the underlying structure(s) in the data. A number of signal analysis methods are commonly used for this purpose; we use the eigenvalue decomposition method (e.g., Elsner and Tsonis, 1996). Signal analysis via eigenvalue decomposi-

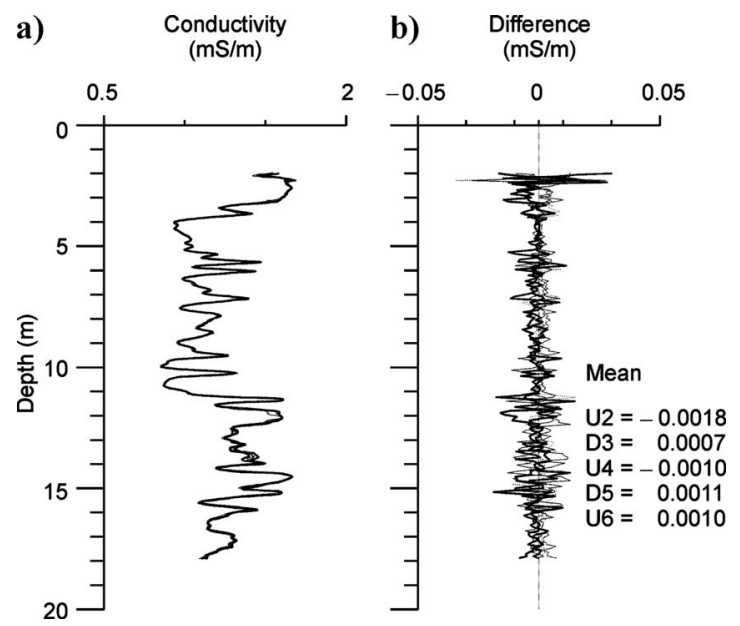

Figure 6. Six downhole and uphole capacitive-conductivity logs acquired in well A1. (a) Data exhibit excellent repeatability. (b) Mean difference between the mean of run 1 and each of the other logging runs. The mean differences over each of the entire logging runs are low - less than about $0.1 \%$. 
tion is known as singular spectrum analysis (SSA) (Vautard and Ghil, 1989; Vautard et al., 1992). SSA is a model-free, nonparametric technique for analyzing time series based on the principles of traditional time-series analysis: signal processing, multivariate statistics, and dynamical systems. The use of singular values and eigenvalues are interchangeable because the singular values are square roots of the eigenvalues.

For a 1D time series or similar type of data series such as a well $\log$, there are three basic parts to the analysis (Schoellhamer, 2001):

1) Transformation of the series $x_{i}$, where sample index $i$ varies from one to $N$ and a maximum lag (or window size) $M$ into a Toeplitz lagged correlation matrix.

2) Perform a singular value decomposition (SVD) of the matrix, which gives the eigenvectors corresponding to the eigenvalues (given in a decreasing order). The eigenvectors account for the variance with the largest number (numerically) accounting for the most variance.

3) Reconstruct the original series based on a number of selected eigenvectors. The choice of the eigenvectors to include is based on the length of the series $N$.

The result of SSA is a decomposition of the original series into a number of additive series, each of which easily can be identified as being part of a modified signal or random noise. SYSTAT's AutoSignal v1.60 software package was used for the analysis; the SSAMTM Toolkit for Spectral Analysis and MATLAB also can be used.

We conduct this structure and scale analysis here independently of lithologic or stratigraphic analyses, but we compare the analyses later in the paper.

\section{Signal components and noise isolation}

The most common use of eigenvalue decomposition is to separate signal from noise, but it can also be used to isolate coherent signal components based on signal strength (Ghil et al., 2002). A singular value or eigenvalue plot versus the index or eigenmode may reveal thresholds of signal components and clearly demarcate signal and noise. The first eigenmodes capture the greatest measure of variance in the data; the lower-numbered eigenmodes usually capture only the noise.

Figure 7 shows a singular spectrum of the capacitive-conductivity data from well C5 at the BHRS. There are two significant log-response components in the spectrum (segment $1, k$ of $1-4$; segment 2, $k$ of 5-20), with eigenvalues from 80 to 1.0 and 1.0 to 0.04 , respectively. The lower eigenvalues $(<0.04)$ represent the noise component of the data. The autoregressive (AR) frequency spectrum for the first seven eigenmodes (indices) shows the two main low spatial frequencies (i.e., long wavelengths of 10.75 and $2.46 \mathrm{~m}$ ). The frequency spectrum of eigenmodes 5-20 (segment 2) shows two significant high spatial frequencies (i.e., short wavelengths of 1.31 and $0.92 \mathrm{~m}$ ).

Figure 8 shows two capacitive-conductivity logging runs acquired in well C5 that are superimposed in each of four tracks, respectively. Track $8 \mathrm{a}$ shows the original data; track $8 \mathrm{~b}$ shows the logs reconstructed from eigenmodes $1-20$; track $8 \mathrm{c}$ shows logs reconstructed from eigenmodes 1-4; and track 8d logs eigenmodes 5-20. There is excellent repeatability in the long-wavelength (track 8c) and short-wavelength (track 8d) data. Therefore, we can interpret the log-response characteristics with a great degree of confidence.

\section{Capacitive versus inductive conductivity at the BHRS}

Figure 9 compares a conductivity log acquired with the Geonics EM39 logging system to the capacitive-conductivity log from well C5. The effect of the high-conductivity clay at the base of the coarse fluvial aquifer at the BHRS has been removed from the cobble-andsand portion of the induction log by treating the logged section as a two-layer system with an instrument-response model (McNeill et al., 1990). This detrending preserves local detail but removes a progressive increase in conductivity by virtue of averaging clay influence within the tool's volume of influence. The induction log shows less sensitivity to stratigraphic changes in the relatively low-conductivity sections (i.e., units 1-3; see Figure 9). The capacitive-conductivity $\log$, however, shows significant variations in the sediments that largely correlate with the porosity stratigraphic units. Correlation between capacitive- and inductive-conductivity data sets is poor except in units 4 and 5 .
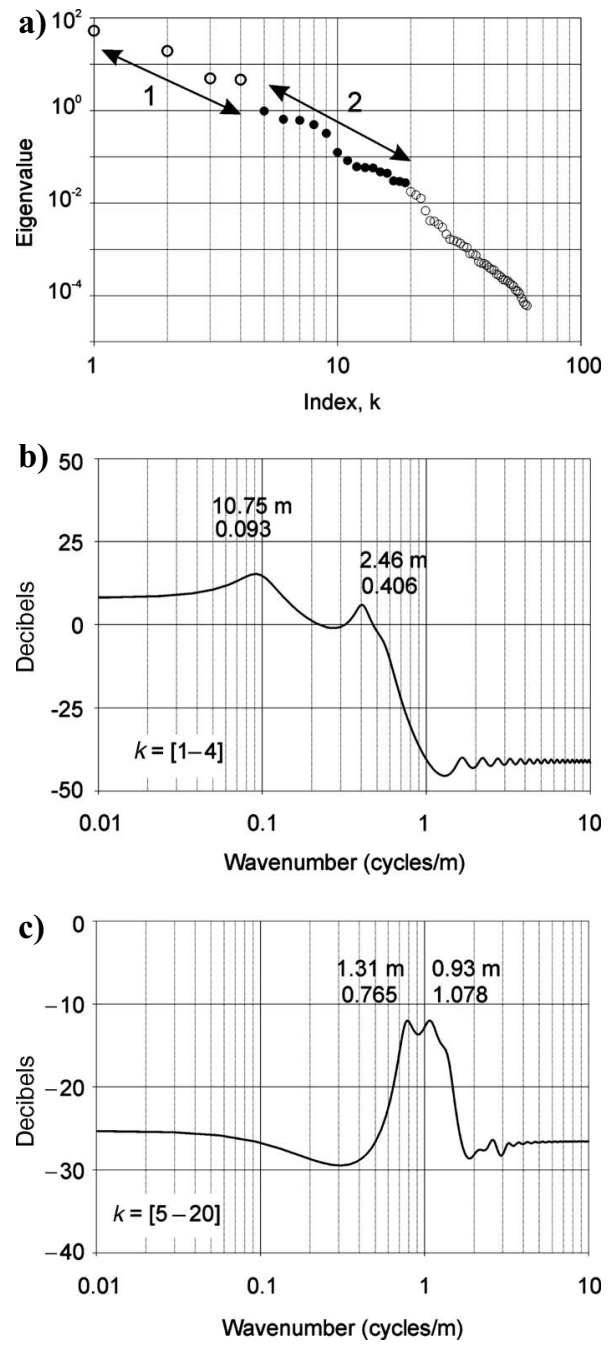

Figure 7. (a) Singular spectrum of the capacitive-conductivity data from well C5. (b) Autoregressive frequency spectrum of eigenmodes 1-4. (c) Autoregressive frequency spectrum of eigencomponents $5-20$. 


\section{CAPACITIVE CONDUCTIVITY VERSUS NEUTRON POROSITY}

The fluvial deposits at the BHRS are composed mainly of cobbles and sand. The sediment grains are virtually insulators with regard to conduction of electrical energy. Figure 10 shows the stratigraphic interpretation from well $\mathrm{C} 5$ with porosity data alone, and with both porosity and capacitive-conductivity data interpreted together. Porosity unit 2 can be subdivided into a lower subunit (electrostratigraphic unit 2A) with relatively higher conductivity and an upper subunit (electrostratigraphic unit 2B) with relatively lower conductivity. The magnitude of conductivity in unit $2 \mathrm{~B}$ is lower than that of unit 3 . A crossplot of conductivity versus porosity (Figure10c) shows a general, positive linear trend and also shows that units $2 \mathrm{~A}$ and $2 \mathrm{~B}$ can be separated.

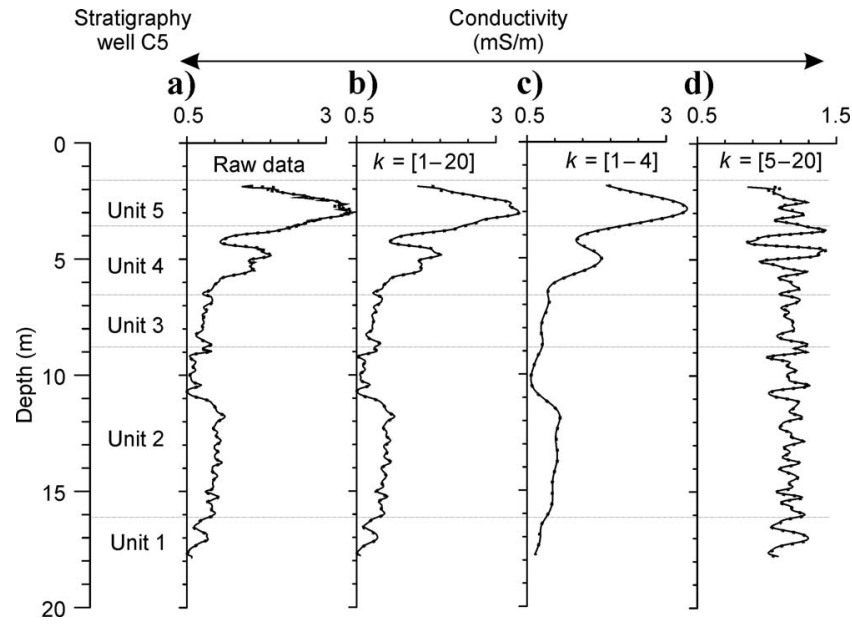

Figure 8. (a) Capacitive-conductivity log (solid line) and repeat log (dotted line) from well $\mathrm{C} 5$; log reconstructed from eigenmodes (b) 1-20, (c) 1-4, and (d) 5-20. Note the very close correspondence between the two logging runs. Stratigraphy interpreted from porosity is shown for reference.

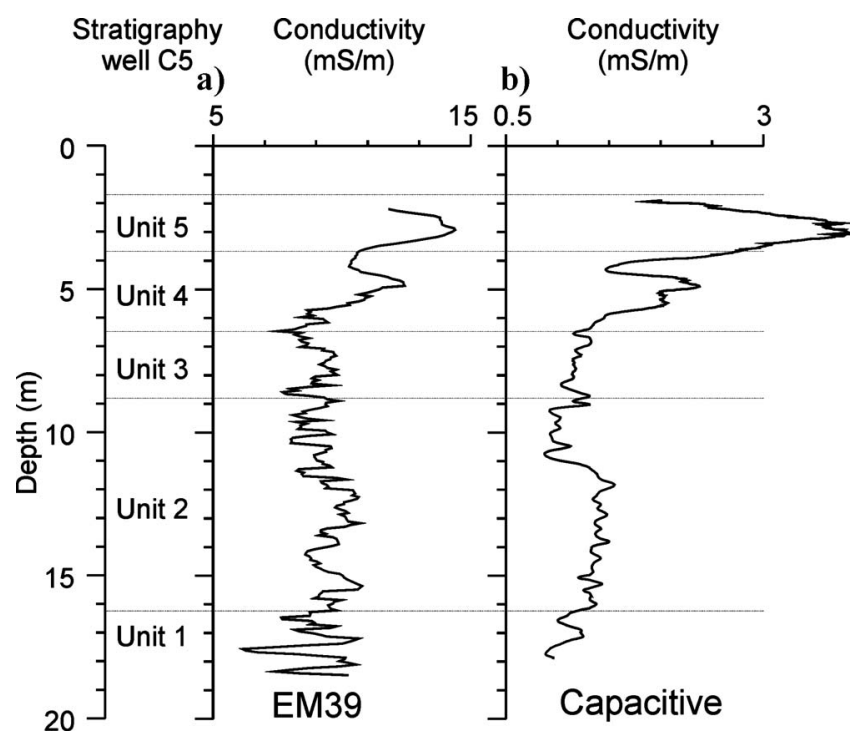

Figure 9. (a) Inductive conductivity log compared to (b) capacitiveconductivity log from well C5. Note the different scales for inductive and capacitive-conductivity logs.
Figure 11 shows the capacitive-conductivity and porosity logs from well C5 reconstructed from eigenmodes 1-20 (Figure 11a), 1-4 (Figure 11b), and 5-20 (Figure 11c). The correlations for eigenmodes $1-20$ and $1-4$ are good except for unit $2 \mathrm{~B}$. The correlations for eigenmodes 5-20 are poor (Figure 11c).
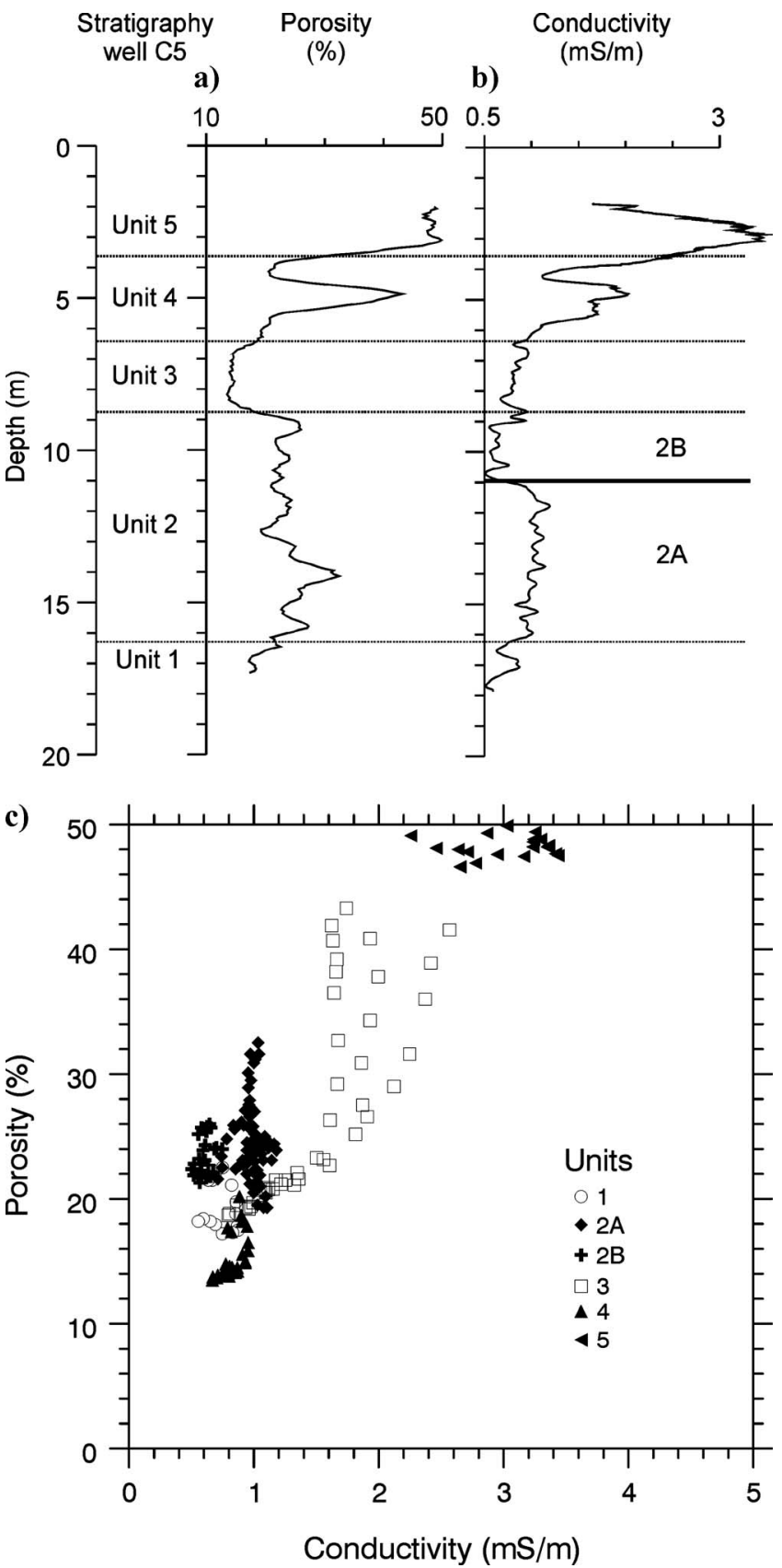

Figure 10. Capacitive-conductivity log and neutron porosity log for well C5, showing stratigraphic interpretation (a) with porosity data alone and (b) with porosity and capacitive-conductivity data interpreted together. Porosity unit 2 can be subdivided into a lower subunit (unit 2A) with relatively higher conductivity and an upper subunit (unit 2B) with relatively lower conductivity. The magnitude of conductivity in unit $2 \mathrm{~B}$ is lower than that of unit 3. (c) A crossplot of conductivity versus porosity shows a general, positive linear trend; it also shows that units $2 \mathrm{~A}$ and $2 \mathrm{~B}$ can be separated. 


\section{REFINING BHRS STRATIGRAPHY WITH CAPACITIVE-CONDUCTIVITY DATA}

As noted, the neutron porosity log has been used to define the stratigraphy at the BHRS (Barrash and Clemo, 2002), and this stratigraphy has been recognized as consistent with independent data sets, including core (Reboulet and Barrash, 2003; Barrash and Reboulet, 2004), radar reflection profiles and volumes (e.g., Clement et al., 2006; Bradford et al., 2009), and crosswell seismic tomography (Moret et al., 2006). In Figures 10-12, however, porosity stratigraphy is compared to the stratigraphy determined from the capacitive-conductivity logs.

Although most unit boundaries correlate well with the two methods, there is a consistent difference in the upper part of unit 2, where a relatively low-conductivity subunit (unit 2B) occurs between the high-conductivity, lower portion of unit 2 below (i.e., unit 2A) and unit 3 above is low conductivity overall but slightly higher conductivity than unit 2B (Figures 10 and 12a-c). The contact between unit $2 \mathrm{~A}$ and unit $2 \mathrm{~B}$ occurs at about $12 \mathrm{~m}$ depth in all cases, and the conductivity threshold between these units is about $0.67 \mathrm{mS} / \mathrm{m}$ (i.e., $\sim 1500 \mathrm{ohm}-\mathrm{m}$ as resistivity). Unit $2 \mathrm{~B}$ is about $2 \mathrm{~m}$ thick and can be identified in wells generally southwest of a line through C6 and $\mathrm{C} 3$ in the central portion of the BHRS (Figure 13). The thickness of unit $2 \mathrm{~B}$ is diminished in wells close to this northeast edge of distribution and absent northeast of this line (e.g., well B3, Figures 12d and 13).

At a smaller scale also (e.g., 0.5-1 m vertical scale, Figures 7 and 11), the capacitive-conductivity logs confirm specific lenses or patches within units $2 \mathrm{~A}$ and 4 by exhibiting anomalies in the same positions that clearly express the same or the opposite sense. For example, a sequence of two 1-m-thick bodies (a lower-porosity, lowerconductivity body overlying a higher-porosity, higher-conductivity body) occurs in unit 4 at 3-3.5 $\mathrm{m}$ and 5-5.5 $\mathrm{m}$ depth in adjacent wells $\mathrm{C} 5$, C4, and B5 (Figures 1, 11, 12a, and b). However, other adjacent wells do not show these sequences, indicating they occur in a limited contiguous region. This type of patchy or lenslike distribution is expected for units 2 and 4 (Barrash and Clemo, 2002; Barrash and Reboulet, 2004; Bradford et al., 2009). Furthermore, the capacitive-conductivity logs provide an independent and convincing rationale for identifying the contact between units 3 and 2 where ambiguous or gradational porosity trends occur, such as in wells B2 and B5 (Figure 12c and b, respectively).

\section{DISCUSSION}

\section{Independent evidence for contrast between units $2 \mathrm{~A}$ and $2 \mathrm{~B}$}

In addition to the observational and distributional evidence for subdividing unit 2 , a distinct change in electrical and dielectric properties has been recognized at the contact between units $2 \mathrm{~B}$ and 2A (i.e., $12 \mathrm{~m}$ depth) between wells $\mathrm{C} 5$ and C6 from an independent investigation with fullin well B3.

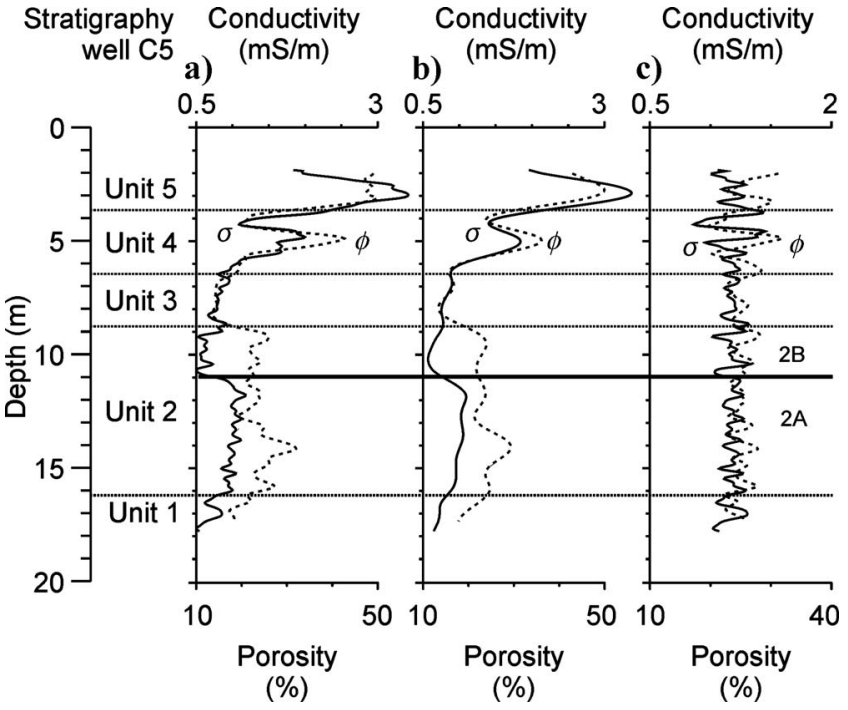

Figure 11. Capacitive-conductivity log compared to the neutron porosity log from well C5. The two data sets are superimposed. Logs are reconstructed from eigenvalue decomposition; reconstruction is from eigenmodes (a) 1-20, (b) 1-4, and (c) 5-20.
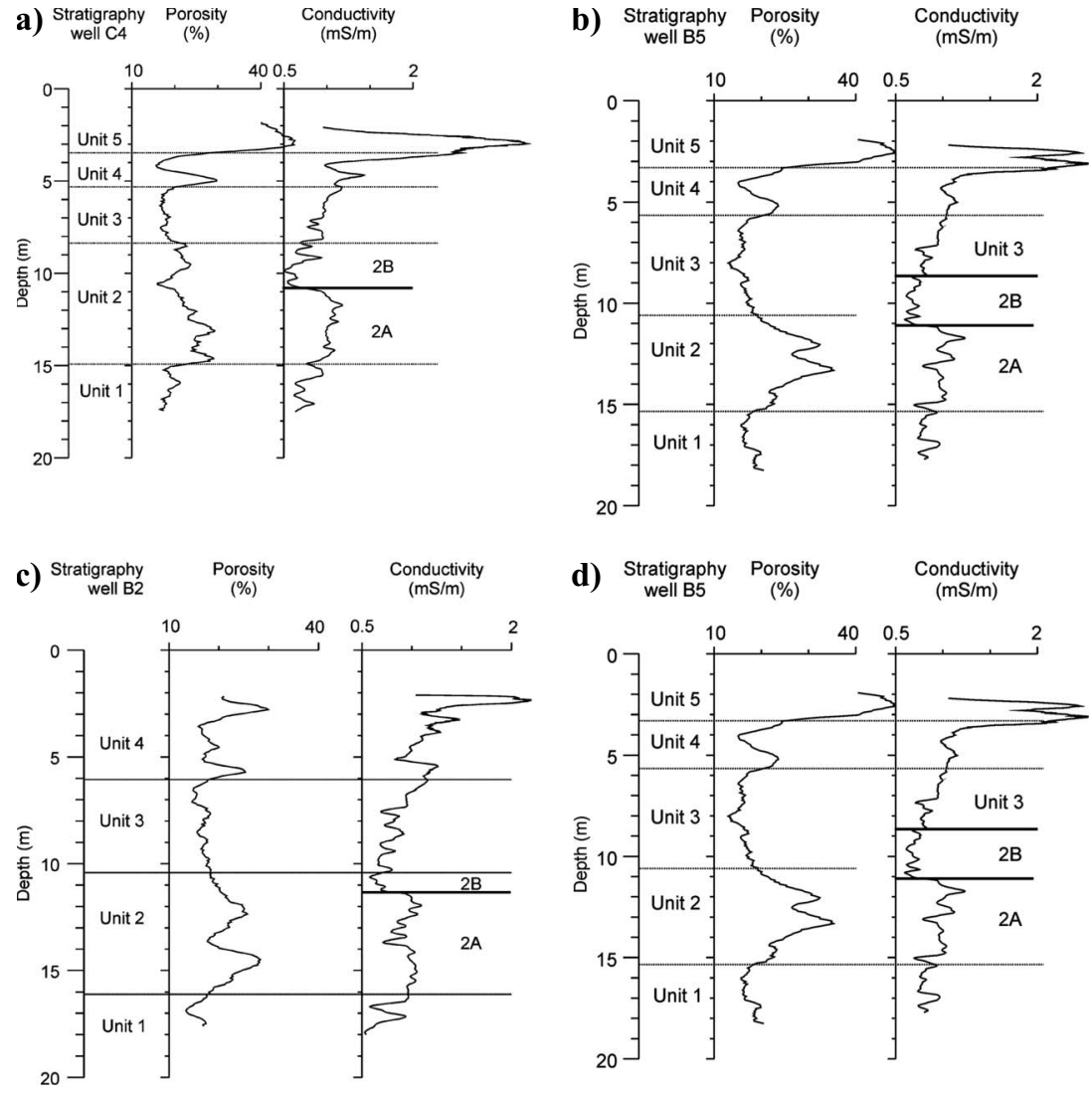

Figure 12. Range of expression of units $2 \mathrm{~A}$ and $2 \mathrm{~B}$ at the BHRS. (a) Unit $2 \mathrm{~B}$ is fully expressed in well $\mathrm{C} 4$ and confirms the unit 2 -unit 3 contact above a zone of anomalously low porosity included in unit $2 \mathrm{~B}$. (b) Unit $2 \mathrm{~B}$ is fully expressed in well B5 and the unit 2B-unit 3 contact provides a basis for relocating the unit 2-unit 3 contact in an interval where porosity is gradational. (c) Unit $2 \mathrm{~B}$ is thinner in well B2 than in wells to the southwest and farther from the edge of occurrence extent (see Figure 13). (d) Unit 2B is absent 


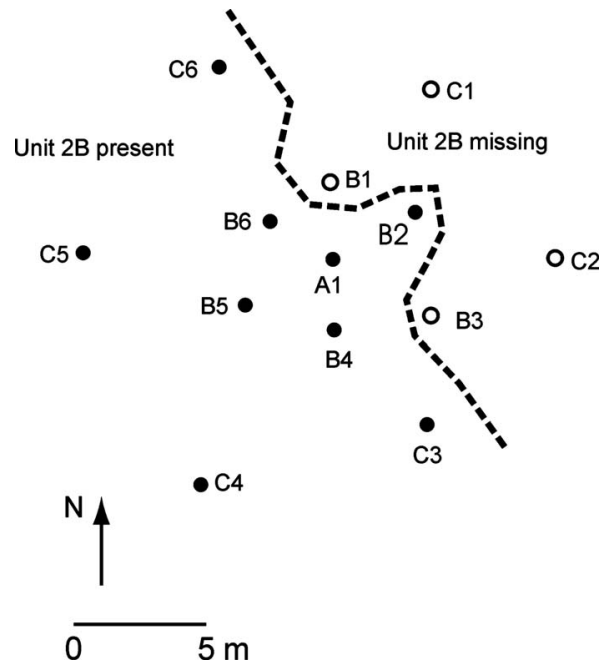

Figure 13. Distribution of unit 2B in the central area of the BHRS.

waveform crosswell radar tomography (see Ernst et al., 2007; their Figure 10). Ernst et al. (2007) note that the distinct contrast in properties at that position is in poor correspondence with otherwise consistent stratigraphic findings based on porosity. This indicates that other factors besides porosity (water-filled pore space) can affect radar signals significantly in these highly resistive granular sediments.

\section{Occurrence of high- and low-conductivity units of similar lithology and porosity}

Other occurrences of relatively higher- and lower-conductivity cobble-dominated units of similar porosity and lithology have been noted in the unconfined aquifer at the Capital Station site in downtown Boise; the site consists of coarse fluvial deposits similar to those at the BHRS (Barrash and Morin, 1997; Barrash et al., 1997). It is not yet clear what causes sediments with otherwise similar porosity and lithology to have different electrical and dielectric properties. The dependence of electrical conductivity and dielectric permittivity on water-filled porosity in coarse (i.e., minimally or nonclay-bearing) sediments composed of resistive grains (or glass beads) is well established. Vertical variations in specific conductivity of borehole fluid at the BHRS are minor (W. Barrash and T. Johnson, personal communication, 2008). Other factors that can affect electrical and dielectric properties of such media include grain shape (Atkins and Smith, 1961; Jackson et al., 1978; Sen, 1984; Jones and Friedman, 2000); grain orientation or packing arrangement (Sen et al., 1981; de Kujper et al., 1996); grain size or surface conductivity (Bolève et al., 2007; Crespy et al., 2007); and grain-size distribution (Robinson and Friedman, 2001; Leroy et al., 2008).

Without speculating on the actual cause for the presence of higher- and lower-conductivity units of similar porosity and lithology at the BHRS or Capital Station, we note the potential for a sedimentologically meaningful cause - such as contrast in grain size or grainsize distribution, grain shape, and/or orientation - which is common between sediment packages in deposits of this type. Approaches to identify and understand the cause for this type of variation are under consideration.

\section{CONCLUSION}

This study presents findings from logging with a prototype capacitive-conductivity borehole tool at the BHRS, a well-characterized research site in a shallow, unconfined aquifer with very-low-conductivity water. Examining such a high-resistivity system provides a good test for the capacitive-conductivity tool because the conventional induction-conductivity tool (known to have limited effectiveness in high-resistivity systems) did not generate expressive well $\operatorname{logs}$ at the BHRS. The capacitive-conductivity tool used at the BHRS had been calibrated previously, and this tool demonstrated highly repeatable, low-noise behavior but poor correlation with results from the induction-conductivity tool in the low-conductivity portions of the stratigraphy where the induction tool was relatively unresponsive.

Singular spectrum analysis of capacitive-conductivity well logs reveals vertical-length scales of structures similar to those found for porosity logs at the BHRS. Also, major stratigraphic units identified with porosity logs (and with independent methods, including core analysis, radar reflection, and seismic tomography) are evident in the capacitive-conductivity logs. In addition, a previously unrecognized subdivision in the upper portion of porosity stratigraphic unit 2 can be identified consistently as a relatively low-conductivity body (electrostratigraphic unit 2B) between unit 3 and the relatively highconductivity lower portion of unit 2 (now identified as electrostratigraphic unit 2A). The unit 3-unit 2B contact in the capacitive-conductivity logs resolves ambiguities in the position of the unit 3-unit 2 contact that occurred in some wells based on porosity logs alone.

Independent identification of the unit $2 \mathrm{~B}$-unit $2 \mathrm{~A}$ contact has been reported from full-waveform crosswell radar tomography between wells C5 and C6 at the BHRS. Also, recognition of cobbledominated units with similar porosity but contrasting electrical conductivity characteristics (as with units $2 \mathrm{~A}$ and $2 \mathrm{~B}$ in porosity stratigraphic unit 2) has been reported in a similar aquifer in downtown Boise. The cause for the variability in electrical (and dielectric) properties in unit 2 is uncertain but may be related to sedimentary features that occur in coarse fluvial deposits such as those at the BHRS.

The capacitive-conductivity tool provides accurate and repeatable measurements of electrical conductivity in a high-resistivity aquifer system. In combination with porosity logs, the tool confirms major and local stratigraphic units and recognizes additional stratigraphic features missed by the porosity log.

\section{ACKNOWLEDGMENTS}

This research was supported by U. S. Environmental Protection Agency (EPA) grant X-970085-01-0. We thank Greg Oldenborger, Geoff Moret, Marc Buursink, and Paul Goggans for help in the field. We also thank Andre Revil for insights from discussions of electrical conductivity influences.

\section{REFERENCES}

Atkins, E. R., and G. H. Smith, 1961, The significance of particle shape in formation factor-porosity relationships: Journal of Petroleum Technology, 13, 285-291.

Atkins, J. E., and E. F. McBride, 1992, Porosity and packing of Holocene river, dune, and beach sands: AAPG Bulletin, 76, 339-355.

Barrash, W., and T. Clemo, 2002, Hierarchical geostatistics and multifacies systems: Boise Hydrogeophysical Research Site, Boise, Idaho: Water Resources Research, 38, 1196, 10.1029/2002WR001436.

Barrash, W., T. Clemo, J. J. Fox, and T. C. Johnson, 2006, Field, laboratory, and modeling investigation of the skin effect at wells with slotted casing, Boise Hydrogeophysical Research Site: Journal of Hydrology, 326, 181-198, doi: 10.1016/j.jhydrol.2005.10.029.

Barrash, W., T. Clemo, and M. D. Knoll, 1999, Boise Hydrogeophysical Re- 
search Site (BHRS): Objectives, design, initial geostatistical results: Proceedings of the Symposium on the Application of Geophysics to Engineering and Environmental Problems (SAGEEP), 389-398.

Barrash, W., and R. Morin, 1997, Recognition of units in coarse, unconsolidated braided-stream deposits from geophysical log data with principal components analysis: Geology, 25, 687-690.

Barrash, W., R. Morin, and D. M. Gallegos, 1997, Lithologic, hydrologic and petrophysical characterization of a coarse-grained, unconsolidated aquifer, Capital Station site, Boise, Idaho: Proceedings of the 32nd Symposium on Engineering Geology and Geotechnical Engineering, 307-323.

Barrash, W., and E. C. Reboulet, 2004, Significance of porosity for stratigraphy and textural composition in subsurface coarse fluvial deposits, Boise Hydrogeophysical Research Site: Geological Society of America Bulletin, 116, 1059-1073.

Bernius, G. R., 1996, Borehole geophysical logs from the GSC Borehole Geophysical Test Site at Bell's Corners, Nepean, Ontario: Geological Survey of Canada Open File Report 3157.

Bolève, A., A. Crespy, A. Revil, F. Janod, and J. L. Mattiuzzo, 2007, Streaming potentials of granular media: Influence of the Dukhin and Reynolds numbers: Journal of Geophysical Research, 112, B08204.

Bradford, J. H., W. P. Clement, and W. Barrash, 2009, Estimating porosity with ground-penetrating radar reflection tomography: A controlled 3D experiment at the Boise Hydrogeophysical Research Site: Water Resources Research, 45, W00D26, doi: 10.1029/2008WR006960.

Bristow, Q., and C. J. Mwenifumbo, 1998, Evaluation of a Russian-designed borehole resistivity probe based on a capacitive principle: Geological Survey of Canada Current Research 1998-D, 65-73.

Clement, W. P., W. Barrash, and M. D. Knoll, 2006, Reflectivity modeling of ground-penetrating radar: Geophysics, 71, no. 3, K59-K66.

Crespy, A., A. Boleve, and A. Revil, 2007, Influence of the Dukhin and Reynolds numbers on apparent zeta potential of granular media: Journal of Colloid and Interface Science, 305, 188-194.

de Kujper, A., R. K. J. Sandor, J. P. Hofman, and J. A. de Waal, 1996, Conductivity of two-component systems: Geophysics, 61, 162-168.

Elliott, B. E., C. J. Mwenifumbo, and G. McDowell, 1999, Borehole geophysical characteristics of the Lady Violet nickel deposit, Sudbury, Ontario: Proceedings of the 12th Annual Symposium on the Application of Geophysics to Engineering and Environmental Problems (SAGEEP), 989997.

Elsner, J. B., and A. A. Tsonis, 1996, Singular spectrum analysis - A new tool in time series analysis: Plenum Press.

Ernst, J. R., A. G. Green, H. Maurer, and K. Holliger, 2007, Application of a new 2D time-domain full-waveform inversion scheme to crosshole radar data: Geophysics, 72, no. 5, J53-J64

Ghil, M., M. R. Allen, M. D. Dettinger, K. Ide, D. Kondrashov, M. E. Mann, A. W. Robertson, A. Sauders, Y. Tian, F. Varadi, and P. Yiou, 2002, Advanced spectral methods for climatic time series: Reviews of Geophysics, 40, $1-41$.

Grard, R., and A. Tabbagh, 1991, A mobile four-electrode array and its application to the electrical survey of planetary grounds at shallow depths: Journal of Geophysical Research, 96, 4117-4123.

Hausrath, E. M., W. Barrash, and E. C. Reboulet, 2002, Water sampling and analysis for the tracer/time-lapse radar imaging test at the Boise Hydrogeophysical Research Site: Report to EPA for grant X-970085-01-0 and to the U.S. Army Research Office for grant DAAH04-96-1-0318, Center for Geophysical Investigation of the Shallow Subsurface Technical Report BSU CGISS 02-02, Boise State University.

Hearst, J. R., and P. H. Nelson, 1985, Well logging for physical properties: McGraw-Hill Book Company.

Heinz, J., S. Kleineidam, G. Teutsch, and T. Aigner, 2003, Heterogeneity patterns of Quaternary glaciofluvial gravel bodies (SW-Germany): Application to hydrogeology: Sedimentary Geology, 158, 1-23.

Jackson, P. D., D. T. Smith, and P. N. Stanford, 1978, Resistivity-porosityparticle shape relationship for marine sands: Geophysics, 43, 1250-1268.

Jones, S. B., and S. P. Friedman, 2000, Particle shape effects on the effective permittivity of anisotropic or isotropic media consisting of aligned or randomly oriented ellipsoidal particles: Water Resources Research, 36, 28212833 .
Jussel, P., F. Stauffer, and T. Dracos, 1994, Transport modeling in heterogeneous aquifers: 1. Statistical description and numerical generation: Water Resources Research, 30, 1803-1817.

Keys, W. S., 1990, Borehole geophysics applied to ground-water investigations: U.S. Geological Survey.

Kuras, O., D. Beamish, P. Meldrum, and R. Ogilvy, 2006, Fundamentals of the capacitive resistivity technique: Geophysics, 71, no. 3, G135-G152.

Leroy, P., A. Revil, A. Kemna, P. Cosenza, and A. Ghorbani, 2008, Complex conductivity of water-saturated packs of glass beads: Journal of Colloid and Interface Science, 321, 103-117.

McNeill, J. D., 1986, Geonics EM39 borehole conductivity meter, theory of operation: Technical note TN-20, Geonics Ltd., http://www.geonics.com/ html/technicalnotes.html, accessed 5 March 2009.

McNeill, J. D., M. Bosnar, and F. B. Snelgrove, 1990, Resolution of an electromagnetic borehole conductivity logger for geotechnical and ground water applications: Technical note TN-25, Geonics Ltd., http://www .geonics.com/html/technicalnotes.html, accessed 5 March 2009.

Moret, G. J. M., M. D. Knoll, W. Barrash, and W. P. Clement, 2006, Investigating the stratigraphy of an alluvial aquifer using crosswell seismic traveltime tomography: Geophysics, 71, no. 3, B63-B73.

Morin, R. H., D. R. LeBlanc, and W. E. Teasdale, 1988, A statistical evaluation of formation disturbance produced by well-casing installation methods: Ground Water, 26, 207-217.

Mwenifumbo, C. J., and Q. Bristow, 1999, Field evaluation of a new borehole resistivity probe using capacitive electrodes: Proceedings of the Symposium on the Application of Geophysics to Engineering and Environmental Problems (SAGEEP), 859-867.

Mwenifumbo, C. J., B. E. Elliott, W. G. Hyatt, and G. R. Bernius, 2005, Bell's Corners Calibration Facilities for downhole and surface geophysical equipment: Geological Survey of Canada Open File Report 4838.

Mwenifumbo, C. J., P. G. Killeen, and B. E. Elliott, 1994, Downhole logging measurements in the Fraser Delta, British Columbia: Geological Survey of Canada Current Research 1994-E, 77-84.

Oldenborger, G. A., M. D. Knoll, P. S. Routh, and D. J. LaBrecque, 2007 , Time-lapse ERT monitoring of an injection/withdrawal experiment in a shallow unconfined aquifer: Geophysics, 72, no. 4, F177-F187.

Othberg, K. L., 1994, Geology and geomorphology of the Boise Valley and adjoining areas, western Snake River Plain, Idaho: Idaho Geological Survey Bulletin, 29 .

Pettyjohn, F., P. Potter, and R. Siever, 1973, Sand and sandstone: SpringerVerlag New York, Inc.

Reboulet, E. C., and W. Barrash, 2003, Core, grain-size, and porosity data from the Boise Hydrogeophysical Research Site, Boise, ID: Center for Geophysical Investigation of the Shallow Service (CGISS) Technical Report 03-02.

Rider, M. H., 1996, The geological interpretation of well logs, 2 ed.: Gulf Publ. Co.

Robinson, D. A., and S. P. Friedman, 2001, Effect of particle size distribution on the effective dielectric permittivity of saturated granular media: Water Resources Research, 37, no. 1,33-40.

Schoellhamer, D. H., 2001, Singular spectrum analysis for time series with missing data: Geophysical Research Letters, 28, 3187-3190.

Sen, P. N., 1984, Grain shape effects on dielectric and electrical properties of rocks: Geophysics, 49, 586-587.

Sen, P. N., C. Scala, and M. H. Cohen, 1981, A self-similar model for sedimentary rocks with application to the dielectric constant of fused glass beads: Geophysics, 46, 781-795.

Timofeev, V. M., A. W. Rogozinski, J. A. Hunter, and M. Douma, 1994, A new ground resistivity method for engineering and environmental geophysics: Proceedings of the Symposium on the Application of Geophysics to Engineering and Environmental Problems (SAGEEP), 701-715.

Vautard, R., and M. Ghil, 1989, Singular spectrum analysis in nonlinear dynamics, with applications to plaeoclimatic time series: Physica, D35, 395424.

Vautard, R., P. Yiou, and M. Ghil, 1992, Singular-spectrum analysis: A toolkit for short, noisy, chaotic signals: Physica, D58, 95-126. 